www.jmscr.igmpublication.org

Impact Factor 5.244

Index Copernicus Value: 83.27

ISSN (e)-2347-176x ISSN (p) 2455-0450

crossref DOI: _https://dx.doi.org/10.18535/jmscr/v4i10.48

\title{
Knowledge and Attitude of Mothers about Diarrhea, ORS and Feeding Practices in Under-Five Children in a Rural Area of Ranga Reddy, Telangana
}

\author{
Authors \\ V Prasanna Rani ${ }^{1}$, Leo Sequeira Vaz $^{2}$, Kusneniwar GN ${ }^{3}$ \\ Department of Community Medicine, MediCiti Institute of Medical Sciences,Share India, \\ Medchal, Telangana, India \\ Corresponding Author \\ Dr V Prasanna Rani \\ Department of Community Medicine, MediCiti Institute of Medical Sciences, Share India, \\ Medchal, Telangana, India \\ Email:prasannaranimims@gmail.com
}

\begin{abstract}
Background: Diarrhea is one of the major cause of morbidity and mortality among under five age group children in India. Mothers knowledge about diarrhea and it's management depends on various factors such as educational status, socio-economic factors and feeding practices. The present study was undertaken to assess the knowledge, attitude regarding diarrhea, ORS and feeding practices in mothers of under-five children.

Methodology: A Cross-sectional study was conducted in a rural area of Rangareddy district among mothers of under-five children in December 2014. A pre designed pre-tested questionnaire was used for data collection among 210 mothers. Data was entered into MS excel sheet \& analyzed by using Epi Info.7.1.3. Version

Results: Among the under-fives mothers $73.3 \%$ know about ORS, 52.8\% knew the correct method of preparing ORS.72.3\% of mothers continued breast feeding during diarrheal episode,41.4\% mothers do not know the cause of diarrhea, $63.1 \%$ think due to mothers dietary habits child can get diarrhea through breast milk.71.9\% are giving some home available fluids during diarrhea.

Conclusion: The present study shows that though most of the mothers were familiar with the term oral rehydration salt, there is a gap in the knowledge and attitude of the mothers regarding diarrhea and ORS. Their knowledge about correct method and amount of ORS is very poor. There is a need to educate the mothers about causes of diarrhea and correct method of ORS preparation.
\end{abstract}

Keywords: Diarrhea, knowledge, feeding practices, mothers, rural area.

\section{INTRODUCTION}

Diarrhea is the fourth leading cause of mortality in children under five years of age. Globally,Every year diarrhea kills around 8,00,000 children under the age of five years ${ }^{1}$. The morbidity and mortality among under-five children, caused by diarrhea is 9 per cent of all deaths worldwide in $2015^{2}$. In developing countries, children under the age of three years suffer from average three episodes of diarrhea per year ${ }^{3}$. In India, around 1.5 million children under-5 years of age died in the year $2012^{4}$. The diarrheal disease was responsible for $13 \%$ of 
the above deaths, resulting in loss of around 300,000 lives every year in India ${ }^{5}$. Approximately $3.1 \%$ of deaths (1.7 million) and $3.7 \%$ of DALYs (54.2 million) worldwide are attributable to unsafe water, poor sanitation and poor personal hygiene (WASH related diseases like diarrhea, dysentery and typhoid). In developing countries in South East Asia $4-8 \%$ of all disease burden is attributable to these factors ${ }^{6}$.

In a cross-sectional survey conducted by UNICEF, prevalence of diarrhea in India was $19.8 \%$ and in Andhra Pradesh it was $27 \%^{7}$. Young age, low socioeconomic status, poor maternal literacy, presence of under-five sibling in the family, birth weight, inadequate breastfeeding, malnutrition, poor sanitation and hygiene practices of the mother are associated with a higher incidence of diarrheal diseases in young children ${ }^{8}$.

Mothers of under five children play a vital role as the primary caretakers and they are the most important persons involved in feeding the children, nursing them when they are sick and maintaining a hygienic environment in and around the house. Their level of knowledge regarding communicable diseases, infections, child nutrition, personal hygiene is crucial to their corresponding practices which will have direct or indirect impact on their child's health'. Various studies which were done to study the knowledge among mothers regarding the use of ORS in diarrhea have reported that maternal literacy had a significant influence on the practice of ORS in diarrhea ${ }^{10-12}$. Literature from various studies reveals that even though the mothers have a good knowledge about diarrhea and ORS but the attitude and practices during the disease are inappropriate $13,14,15,16$. Diarrhea is a both preventable and treatable disease, but due to improper knowledge of mothers and their misdirected approach towards the disease management results into severe dehydration and death ${ }^{17}$. The number can be dramatically reduced through critical therapies such as prevention and treatment of dehydration with ORS and fluids available in the home, breastfeeding, continued feeding, zinc supplementation for 10-14 days ${ }^{18}$.
According to District level household Survey-4 (2012-13), 4.2\% of under-five children suffered from diarrhea in rural Andhra Pradesh. And 48.6\% children with diarrhea received ORS in rural Andhra Pradesh ${ }^{19}$. Oral rehydration is yet to achieve its full potential in preventing diarrhea deaths due to many factors such as poor socio-economic status, lack of knowledge among care givers and failure to provide therapy when needed ${ }^{20}$. Most of the times the health care workers do not emphasize the role, benefits and method of preparation of ORS, as a result of which mothers do not know the right method of preparation of ORS and do not understand the need to give ORS to the child ${ }^{21}$. Many studies have been done in different areas of India about mother's knowledge about diarrhea, use of ORS, impact of mother's knowledge on the management of diarrhea but very few studies have been done in districts of Telangana state. So the objectives of the present study was to assess the knowledge about diarrhea, ORS, the attitude and feeding practices of mothers during diarrheal episodes in a rural village of Telangana.

\section{METHODOLOGY}

We conducted a Community based Cross- sectional study during the period of December 2014 to January 2015. As per 2011 census, the total population of Rangareddy district is 5,296,741 with a population density of $707 / \mathrm{km}^{2}$. About $29.78 \%$ population of Rangareddy districts lives in rural areas of villages. The total Rangareddy district population living in rural areas is $1,577,569$. Child population in the age $0-6$ is 192,848 in rural areas of which males were 99,495 and females were 93,353. Our study area was Girmapur village of Medchal Mandal in Rangareddy district with a total population of 2098, total Households of 514 and total under-five population of 238 (census 2011). The survey team consisted of a Health care worker and doctors.

All the households with at least one under-five child during a house-to-house survey were included for data collection. All the mothers willing to participate were included in the study. Mothers who 
were not willing and who did not have atleast one under-five child were excluded from the study. The sample size was calculated based on the Percentage of awareness about diarrhea among the rural women in Andhra Pradesh, DLHS-4 (2012-13) which is $63.5 \%$. A sample size of 212 was calculated by the formula $4 \mathrm{pq} / \mathrm{L}^{2}$ taking $63.5 \%$ as Prevalence(P), an allowable error (L) of $11 \%$ (of the prevalence) and with $10 \%$ of non-respondents. Institutional ethical committee approval was taken before starting the data collection.

The interviewees were informed about the purpose and nature of the study in their local language and the verbal informed consent was obtained before interviewing each participant. A pre-tested, semi structured questionnaire was used for data collection. The questionnaire was divided into 3 parts covering the socio-demographic details, knowledge about causes of diarrhea, Knowledge of ORS, preparation method, volume of ORS and attitude and health seeking behavior during illness, hand washing practices, feeding practices in underfive children. The questions were framed into forty multiple choice questions giving more than one option for all the questions in their local Telugu language.

During a house to house survey a total of 210 mothers were interviewed. To identify the underfive children we took help of the local Anganwadi workers in the village. Mothers who were present at the time of data collection were interviewed regarding the knowledge, attitude and Feeding practices during diarrhea, correct preparation and dosage of ORS by using personal interview method in Telugu which was their local language.

\section{STATISTICAL ANALYSIS}

Data was entered into MS excel sheet \& Analysis was done by using Epi Info 7.1.3.version. Descriptive statistics was applied, demographic data and level of knowledge regarding ORS was described in terms of frequency and percentage, Chi-square test was used to analyze categorical data. Tables and graphs were generated using MS Word and MS Excel. A p value of $<0.05$ was considered statistically significant.

\section{RESULTS}

In our study mean age of the mothers is $24.1 \pm 3.2$. Majority of the mothers were in the age group of 15--24 years of age. Mean age of the child was 2.0 \pm 1.1. Among all mothers $58.6 \%$ of mothers were having one under-five child, $38.6 \%$ were having 2 under-fives and $2.8 \%$ mothers were having 3 underfives during the study period. The sociodemographic details (Table 1) of the mothers suggest that $92 \%$ belonged to Hindu religion. Most of the mothers $(88 \%)$ were educated but majority $(71 \%)$ of them were unemployed.

Table 1: Socio-Demographic details of the mothers

\begin{tabular}{|c|c|}
\hline $\begin{array}{r}\text { Religion } \\
\text { Hindus } \\
\text { Muslims } \\
\text { Christians } \\
\text { Others }\end{array}$ & $\begin{array}{cl}\text { No. } & (\%) \\
184 & (92) \\
19 & (15) \\
5 & (4) \\
2 & (1)\end{array}$ \\
\hline $\begin{array}{c}\text { Education of mother } \\
\text { Literate } \\
\text { Illiterate }\end{array}$ & $\begin{array}{cc}184 & (88) \\
26 & (12)\end{array}$ \\
\hline $\begin{array}{c}\text { Occupation of mother } \\
\text { Employed } \\
\text { Unemployed }\end{array}$ & $\begin{array}{cc}62 & (29) \\
148 & (71) \\
\end{array}$ \\
\hline $\begin{array}{l}\text { Source of drinking water } \\
\text { Municipal supply } \\
\text { Bottled water }\end{array}$ & $\begin{array}{ll}91 & (43) \\
119 & (57) \\
\end{array}$ \\
\hline $\begin{array}{l}\text { Consuming drinking water } \\
\text { With treatment } \\
\text { Without treatment }\end{array}$ & $\begin{array}{cc}70 & (38) \\
140 & (62)\end{array}$ \\
\hline $\begin{array}{l}\text { Above poverty line families } \\
\text { Below poverty line families }\end{array}$ & $\begin{array}{cc}92 & (39) \\
118 & (61)\end{array}$ \\
\hline
\end{tabular}

Majority (35\%) of the children belonged to Lower middle class (III) as per BG Prasad's Socioeconomic Status classification ${ }^{34}$. $23 \%$ of them belonged to upper middle class, $7 \%$ belonged to upper class, $29 \%$ of them belonged to Upper lower and $7 \%$ belonged to lower class. Majority $(61 \%)$ of the families belonged to below poverty line (BPL) according to their annual family income and $39 \%$ of them were belonged to above poverty line (APL). Among the 210 respondents, 185(88\%) were practicing hand wash with soap \& water before preparing food for the child. 94 (45\%) of the women said they never reheat the prepared food for the 
child. Among 210, 104 (49\%) were giving Cow / buffalo milk to the child. Only 40 (19\%) were giving bottle feeding to the child.

In the present study majority $(56.7 \%)$ of the households were using Purified Bottled water for drinking. 9\% from Piped water,19.5\% from Public tap, $14.8 \%$ were drinking bore well water. Among all the mothers $24.3 \%$ were boiling the water for the children before consumption. Various other methods used for treating the water were straining with cloth (2.9\%), Water filters (11.1\%). $61.9 \%$ of them were using without any treatment. $89.5 \%$ mothers were covering the water vessels. $65.7 \%$ said they use handled mug/glass for taking out the water, where as $25.2 \%$ mothers were dipping the hands into the water containers. Majority of the mothers $(83 \%)$ were maintaining cleanliness in and around the houses. Most (91\%) of them were using Sanitary latrines for defecation. $9 \%$ were going for Open defecation.

\section{Knowledge about diarrhea}

Among the under-fives, 101 (48.5\%) had suffered with diarrhoea in the past 6 months before the survey. Among 210 mothers 123 (59\%) knew the correct cause of diarrhea. Few among the mothers, $66(32 \%)$ thought that breast milk causes diarrhea in children. 132 women (63\%) thought due to mothers dietary habits diarrhoea passes through breast milk. Table 2 shows, out of 123 mothers who knew the causes of diarrhoea, 61 (29\%) thought that unhygienic food was one of the main cause of diarrhea in children.

Table 2: Causes of diarrhea according to mothers

\begin{tabular}{|l|l|}
\hline \multicolumn{1}{|c|}{ Causes of diarrhea } & No (\%) \\
\hline By dirty /contaminated water & $31(14.8)$ \\
\hline By unhygienic food & $61(29.1)$ \\
\hline $\begin{array}{l}\text { By unhygienic conditions in and around the } \\
\text { house }\end{array}$ & $10(4.8)$ \\
\hline Tooth eruption & $21(9.9)$ \\
\hline
\end{tabular}

\section{Attitude and Feeding practices during diarrhea}

Out of the 210, (49\%) 103 mothers were feeding only with breast milk during diarrhea. Only 72
(34\%) mothers were giving normal food during diarrhea. $23(11 \%)$ mothers were not giving anything orally during diarrhea.

Among all 210 mothers 145 (69\%) were taking their child to a pediatrician during any illness (Figure 1). Majority of the mothers (87\%) said that they will take the child to a physician after child had more than 3 stools in a day (Figure 2). 67 (31\%) of the mothers were giving coconut water and 38 (18\%) of them were giving Rice water during diarrhea (Figure 3). About 60 (28\%) mothers were giving bottled soft drinks to the child during diarrhea. 152 (72\%) mothers out of 210 were continuing breast feeding during diarrhoeal episodes. Among all the respondents 97 (46\%) mothers said that they will start giving normal food only after an episode of diarrhea subsides.

Fig.1 Distribution of health seeking behavior of mothers during illness

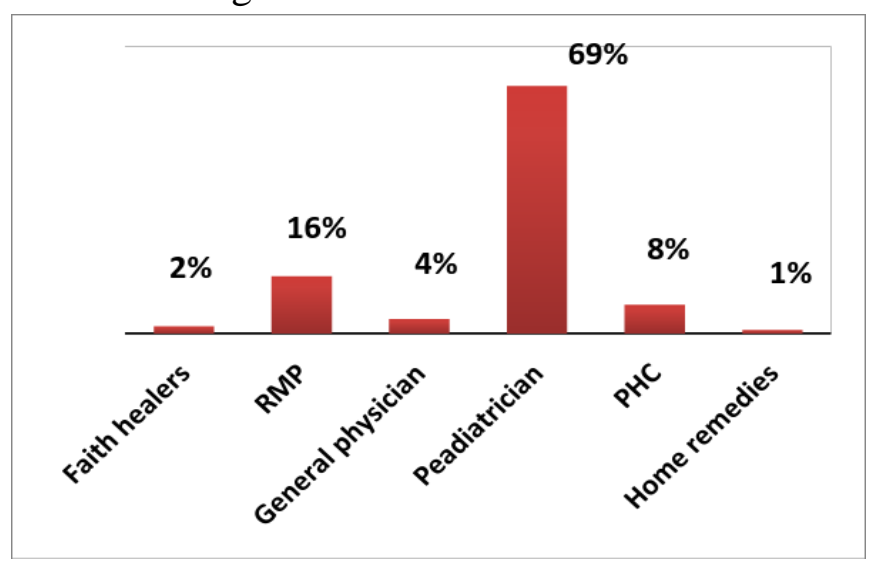

Fig. 2: Mothers attitude in consulting the physician during child illness

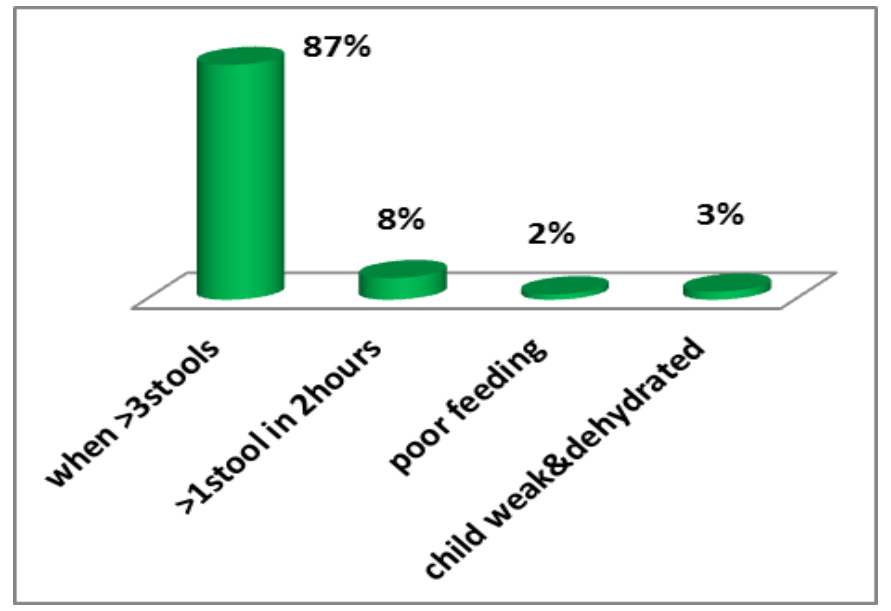


Fig.3: Home available fluids given during diarrhea

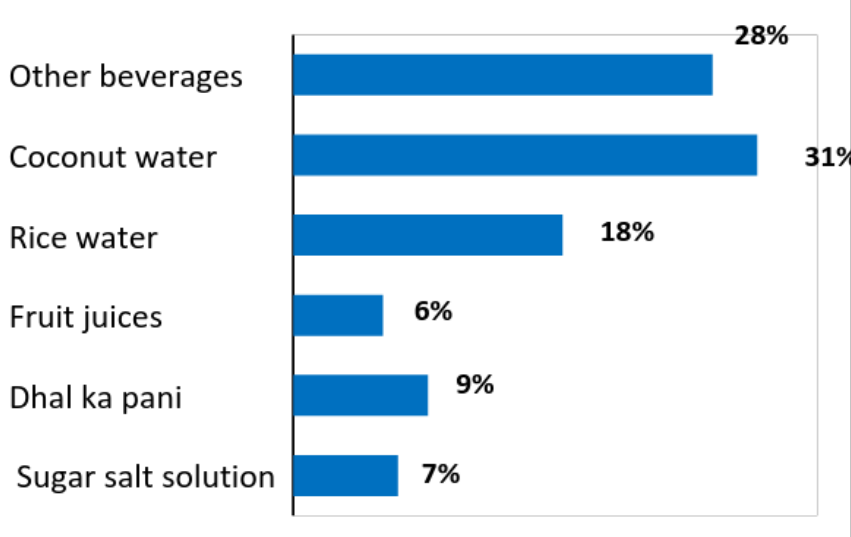

\section{Knowledge about ORS}

Among 210 mothers 154 (73\%) were aware of ORS as shown in Table3.There was a significant association between knowledge about ORS, mother's education and mother's occupation.(Table 5) Among the 154 only 62 (40\%) mothers were aware of correct method of preparation of ORS, 92 $(60 \%)$ were aware of correct amount of ORS to be given to the child, $89(58 \%)$ think that ORS should be stopped immediately after decreased frequency of Loose stool, 32 (21\%) think that giving excess ORS will harm the child during diarrhea and 45 (29\%) mothers said they don't know about harmful effects of ORS. Most of the mothers reported their major source of information about diarrhea was from the Doctors $(34.3 \%)$. other sources were Television (20\%) from Mothers (22\%), Media (21\%) and least from health care workers (2.9\%).

Out of 210 mothers 82 (39\%) were not aware of $\mathrm{Zn}$ tabs. $126(60 \%)$ were given $\mathrm{Zn}$ tablets at health facilities but they did not use. Among all, very few mothers (1\%) were giving Zinc tablets during diarrheal episode. Most of them (39.5\%) were not aware about the role of Zinc tables.

As shown in Table4, a significant association was observed between consumption of treated water, washing of hands before cooking and mother's education ( $p$ <.05). The causes of diarrhea, Continuation of breast feeding during diarrhea and mother's education did not show any significant association
Table 3: Knowledge about ORS

\begin{tabular}{|l|l|}
\hline Variable & No (\%) \\
\hline Aware of ORS & \\
Yes & $154(73 \%)$ \\
No & $56(27 \%)$ \\
\hline Correct preparation of ORS & \\
Yes & $62(40 \%)$ \\
No & $92(60 \%)$ \\
\hline Correct amount of ORS & \\
Know & $92(60 \%)$ \\
Don't know & $62(40 \%)$ \\
\hline Stop ORS on reduced frequency of & \\
stools & $89(58 \%)$ \\
Yes & $65(42 \%)$ \\
No & \\
\hline Harm in giving excess ORS & \\
Yes & $32(21 \%)$ \\
No & $77(50 \%)$ \\
Don't know & $45(29 \%)$ \\
\hline
\end{tabular}

The association of Knowledge of mothers on breast milk as a cause of diarrhea and mother's education was tested by using chi-square test which came significant with $(\mathrm{p}<0.05)$.

Table 4: Distribution of socio-demographic factors of mothers and the Knowledge and Practices during diarrhea

\begin{tabular}{|c|c|c|c|}
\hline \multirow[b]{2}{*}{ Variables } & \multicolumn{2}{|c|}{$\begin{array}{l}\text { Mother's } \\
\text { education }\end{array}$} & \multirow{2}{*}{$\begin{array}{c}\mathbf{P} \\
\text { value }\end{array}$} \\
\hline & Literate & Illiterate & \\
\hline $\begin{array}{l}\text { Consumption of } \\
\text { treated water } \\
\text { With treatment } \\
\text { Without treatment }\end{array}$ & $\begin{array}{l}55 \\
129\end{array}$ & $\begin{array}{l}15 \\
11\end{array}$ & 0.004 \\
\hline $\begin{array}{l}\text { Washing of hands } \\
\text { before cooking } \\
\text { Yes } \\
\text { No }\end{array}$ & $\begin{array}{r}170 \\
14\end{array}$ & $\begin{array}{l}15 \\
11\end{array}$ & 0.0001 \\
\hline $\begin{array}{ll}\text { Causes } & \text { of } \\
\text { diarrhea } & \\
\text { Aware } & \\
\text { Not aware } & \end{array}$ & $\begin{array}{r}100 \\
23\end{array}$ & $\begin{array}{r}84 \\
3\end{array}$ & 0.0009 \\
\hline $\begin{array}{l}\text { Breast milk as a } \\
\text { cause of diarrhea } \\
\text { Yes } \\
\text { No }\end{array}$ & $\begin{array}{c}52 \\
132\end{array}$ & $\begin{array}{l}14 \\
12\end{array}$ & 0.008 \\
\hline $\begin{array}{ll}\text { Continued breast } \\
\text { feeding } & \text { during } \\
\text { diarrhea } & \\
\text { Yes } & \\
\text { No } & \\
\end{array}$ & $\begin{array}{r}135 \\
49 \\
\end{array}$ & $\begin{array}{r}17 \\
9 \\
\end{array}$ & 0.393 \\
\hline
\end{tabular}

CHI- SUQARE TEST WAS USED 
Table 5: Distribution of mothers according to socio-demographic factors and the Knowledge about ORS

\begin{tabular}{|l|c|c|c|}
\hline \multirow{2}{*}{ Variables } & \multicolumn{2}{|c|}{ Knowledge about ORS } & \multirow{2}{*}{ P value } \\
\cline { 2 - 3 } & Present & $\begin{array}{c}\text { Not } \\
\text { present }\end{array}$ & \\
\hline Mothers & & & \multirow{2}{*}{0.05} \\
$\begin{array}{l}\text { Education } \\
\text { Literate }\end{array}$ & 139 & 45 & \\
illiterate & 15 & 11 & \\
\hline Mothers & & & \multirow{2}{*}{0.01} \\
Occupation & 38 & 24 & \\
Employed & 116 & 32 & \\
unemployed & 69 & 23 & 0.629 \\
\hline $\begin{array}{l}\text { APL Families } \\
\text { BPL Families }\end{array}$ & 85 & 33 & \\
\hline CHI-SQUARE TST & & \\
\hline
\end{tabular}

CHI-SQUARE TEST WAS USED

In Table 5 it can be seen that the association between knowledge about ORS,Mother's educational status and mothersoccupational status came significant with a $\mathrm{p}$ value $<0.05$.

\section{DISCUSSION}

Our study shows that majority (57\%) of the mothers were using Bottled filtered water for drinking. The proportion of mothers treating the water before consumption for the child was reported as $38.1 \%$ which was lower than a study done in Rural Salem $^{22}$. Most of them $(61.9 \%)$ were giving without any water treatment which is lower than rural Madhya Pradesh study ${ }^{23}$. Even though they are consuming purified municipal water for drinking there is a chance of water contamination during the rainy season and during handling the water at home. So we must advice the mothers to practice treating the water before consumption.

Knowledge about different modes of spread of diarrhea was adequate among half of the mothers which was higher than a study conducted in urban slums of Bankura ${ }^{24}$. Unhygienic food $(29.1 \%)$ was considered as a major cause of infection which is higher than studies done in rural Madhya Pradesh ${ }^{23}$ and in rural Haryana ${ }^{28}(23 \%)$. Dirty or contaminated water was considered as second most common cause of diarrhea by the mothers which was lower than the Madhya pradesh ${ }^{23}$ study.
In our study we found that all the mothers had good knowledge and attitude for personal hygiene factors such as washing hands before cooking which was reported as $88 \%$ was comparable with a study done in urban slums of Delhi ${ }^{25}$. Though the knowledge regarding the cleanliness in and around the house was good among the mothers, majority $(41.4 \%)$ of them do not know the important causes of diarrhea. Our study has noted another important finding that majority of the households, $91.4 \%$ were using sanitary latrines which were higher than the results of a study in rural Salem ${ }^{22}(62.7 \%)$ and very few $(8.6 \%)$ were going for open defecation which was lower than rural Salem study ${ }^{22}$ (32.3\%). This attitude of using sanitary latrines by the households will reduce and prevent the fecal transmission of disease which is one of the common causes of diarrhea. This positive finding can also be attributed to better educational levels of mothers and better facilities available in urban areas.

Mother's education is one of the most important determinantof child survival. Among all the mothers $88 \%$ of them were educated in which more than half had finished their higher school education. This is similar with the results of a study done in Karna$\operatorname{taka}^{26}$. This also showed a significant association with Good Knowledge about ORS (Table 5).

Even though the literacy status was high among the mothers, only $29 \%$ of them were employed. Majority $(71 \%)$ of the mothers were housewives and looked after their children and domestic work. So the educational status and unemployment status of the mothers were the two major reasons behind a good knowledge about ORS.

Exclusive breastfeeding was seen in $49 \%$ of the mothers which is similar with a study done in rural Aligarh $^{27}$ (51\%), but much lower than a study conducted in rural Haryana $(85.5 \%)^{28}$. Breast milk is the best management of fluid replacement in a breast fed child with diarrhea and should be continued along with other oral rehydration solutions.

Practices like continued normal solid food during diarrhoeal episode in our study was about $34.3 \%$ which was very similar to studies conducted in Bengaluru $^{29}(34.3 \%)$ and $\operatorname{Varanasi}^{30}(38.2 \%)$, but 
lower than a study done in rural Haryana ${ }^{28}(65 \%)$. Regular normal feeds were reduced by few mothers $(17 \%)$ which is similar to a study in Puduccherry ${ }^{31}$ $(19 \%)$ but lower than a study in rural Haryana ${ }^{28}$ (35\%). Total restriction of fluids by mouth was practiced by $11 \%$. Mothers were not giving anything to drink by mouth during the episodes which was lower than a study in rural Hodalpur of Uttar Pradesh $^{32}$. Among all, 45.7\% mothers reported they will restart giving normal food only after the diarrhea subsides. In our study majority (72\%) of mothers were aware of home available fluids which was lower than a study conducted in Puduccherry ${ }^{31}$ (82.9\%).

As far as health seeking behaviour is concerned, majority (69\%) of the Mothers consulted pediatric specialists in private practice followed by RMPs (16\%) during diarrhoeal episodes which was similar to a study in Delhi slums ${ }^{25}$. Very few children (8\%) were taken to the government facilities. Even though the health seeking behaviour of the mothers was appreciable, most of them went to the private practitioners. More studies should be carried out to find out the factors leading to non utilizationof available government facilities.

The Knowledge about ORS among mothers in our study was $73.3 \%$. Similar observations were made by other authors in Delhi ${ }^{25}(70 \%)$ and rural Aligarh $^{27}$ (72\%), but lower than studies done in Puducherry $^{31}$ (78\%). However, having good knowledge about ORS does not always imply that the mothers could prepare the ORS solution correctly. As in our study, mothers who were aware of ORS only $40 \%$ of were able to prepare it correctly which was higher than studies conducted in Delhi ${ }^{25}$ (39\%) and Rural Aligarh ${ }^{27}(30 \%)$ but lower than study in rural Haryana ${ }^{28}(48 \%)$. Out of all mothers who are aware of ORS, only $92(60 \%)$ were aware of correct amount of ORS which is lower than a study conducted in rural Haryana ${ }^{28}$. Majority (42\%) of them do not know how many times the ORS should be given during diarrhoeal episode. Majority of the mothers (58\%) used to stop ORS on reduced frequency of loose stools which was higher than a study done in Puduccherry ${ }^{31}$
$(50 \%)$ but lower than a Delhi $\operatorname{study}^{25}(62 \%)$. A significant association was found between ORS knowledge, mother's education and mother's occupation which was similar in comparision with a study in Bengaluru ${ }^{29}$.

The major source of information about diarrhea and ORS was from Doctors (34.3\%) which was lower than a study conducted in rural Vasind ${ }^{33}(56.4 \%)$. other sources were Television (20\%) which was higher than a study in rural Vasind ${ }^{33}(6.7 \%)$. This study shows the role of health care workers was much less $(2.9 \%)$ in comparision to the study in rural Vasind $^{33}(25.7 \%)$. There is a need of increasing awareness regarding the effective role of health workers in prevention and management of diarrhea. The media and television can also be used as the best mode for propagating the information regarding diarrhea and ORS.

\section{CONCLUSIONS}

From this study it can be concluded that knowledge and attitude of mothers regarding ORS and diarrhea is satisfactory as majority of the participants were using ORS during diarrhea, continued breast feeding during diarrhea, washing hands before cooking food for the children. Knowledge about correct preparation, correct amount of ORS and stopping ORS on reduced diarrheal episodes is insufficient and need to be addressed.

Demonstration of correct preparation of ORS solution should be inbuilt in the health education package of the Oral Rehydration Therapy for Diarrheal diseases. Health care providers must emphasize about the role of ORS and Zinc tablets in the prevention of dehydration, so that mothers could correctly prepare and give correct volume of ORS to the child.

\section{ACKNOWLEDGEMENT}

We acknowledge the anganwadi workers for their cooperation and the mothers for their participation and sharing necessary information. 


\section{REFERENCES}

1. Diarrhoea remains a leading killer of young children, despite the availability of a simple treatment solution . Available at http:/data.unicef.org/chi-ld-health/diarrhoealdisease.html\#inline1

2. United Nations Children's Fund. Levels \& Trends in Child Mortality. Estimates Developed by the UN Inter-Agency Group for Child Mortality Estimation. New York, USA: UNICEF; 2013.

3. WHO. Media Centre. Diarrhoeal disease. Fact sheet $\mathrm{N}^{\circ}$ 330. 2013. Available at: http://www.who.int/mediacentre/factsheets/f s330/en/. Accessed 25 August 2013.

4. Rashid, S. F., Hadi, A., Afsana, K., \& Begum, S. A. (2001). Acute respiratory infections in rural Bangladesh: cultural understandings, practices and the role of mothers and community health volunteers. Trop Med Int Health, 6(4), 249- 255.

5. Saini, N. K., Gaur, D. R., Saini, V., \&Lal, S. Acute respiratory infections in children: a study of knowledge and practices of mothers in rural Haryana. J Commun Dis, 1992, 24(2), 75-77.

6. The World Health Report. Chapter 4, 2015. Available at: http://www.who.int/whr /2002/chapter4/en/index7.html. Accessed June 2015.

7. Unicef survey of 10 districts, management practices of childhood diarrhea in india ,new delhi, unicef 2009 .

8. Park K. Textbook of Preventive and Social Medicine. $23^{\text {rd }}$ edition Jabalpur, India: BanarsidasBhanot; 2015. Epidemiology of communicable disease; pp. 221-224.

9. Bhatia, V., Swami, H. M., Bhatia, M., \& Bhatia, S. P. (1999). Attitude and practices regarding diarrhoea in rural community in Chandigarh. Indian J Pediatr,66(4),499-503.

10. Sultana A, Riaz R, Ahmed R, Khurshid R. Knowledge and attitude of mothers regarding oral rehydration salt. J Rawalpindi Med Coll. 2010;14(2):109-11.
11. Rasania SK, Singh D, Pathi S, Matta S, Singh S. Knowledge and attitude of mothers about oral rehydration solution in few urban slum of Delhi. Health Popul Perspect Issues. 2005;28(2):100-7.

12. Dhadave MM, Kumar A, Reddy S, Vijayanath V. A study on diarrhea related practices awareness of ORS among mothers of under-five children attending OPD, CHTC, Rajpur. J Pharm Biomed Sci. 2012;19(19):1-3

13. Kumar, D., Goel, N. K., Kalia, M., Swami, H. M., \& Singh, R. (2008). Gap between awareness and practices regarding maternal and child health among women in an urban slum community. Indian J Pediatr, 75(5), 455-458.

14. World Health Organization, 'Children: Reducing mortality',www.who.int/mediacentre/factsheets/fs178/en/index.html, accessed 17 July 2012.

15. UN WATER- 'Sanitation for all-Making the right a reality', www.sanitationdrive,2015/ /Planners-Guide- Fact -Sheet -4-English.pdf

16. Sood, A. K., \&Kapil, U. (1990). Knowledge and practices among rural mothers in Haryana about childhood diarrhea. Indian $J$ Pediatr, 57(4), 563-566.

17. Rehan SH, Gautam K, Gurung K. KAP of mothers regarding diarrhea. Indian $\mathrm{J}$ prevSoc Med 2003; 34:1-6.

18. Munos MK, Walker CL, Black RE. The effect of oral rehydration solution and recommended home fluids on diarrhoea mortality. International Journal of Epidemiology. 2010;39:i75-87.

19. International Institute for Population Sciences (IIPS) and Macro International. District Level Household and Facility Survey(DLHS -4) ,2012-13. State fact sheet Andhra Pradesh.

20. The management of diarrhoea and use of oral rehydration therapy: A joint $\mathrm{WHO} /$ UNICEF statement. 2nd ed.WHO.1985. Available 
http://hetv.org/pdf/management-ort.pdf.

Accessed 16 August 2013.

21. Rajendra Kumar Gupta, GautamLalNagori, Devendra Kumar Jain. Study of knowledge of mothers regarding use and preparation of ors in acute diarrhoea.$J$ of Evolution of Med and Dent Sci 2015/ Vol. 4/ Issue 20/ Mar 09.

22. Ravi Pachori. Drinking water and sanitation: household survey for knowledge and practice in rural area, Magudanchavadi, Salem district, India.Int $\mathrm{J}$ Community Med Public Health, 2016. Jul;3(7):1820-28.

23. M Bhattacharya, V Joon, V Jaiswal. Water handling and sanitation practices in rural community of Madhya Pradesh: a knowledge, attitude and practice study.Indian J. Prev. Soc. Med Vol. 42 No.1 January- March, 2011.Page 93-97.

24. Eashingazi et al.,Can mothers care for acute diarrhoeal disease of their under five children effectively at home? A cross sectional study in slum community in Bankura. J of Evidence Based Med \&Hlthcare, 2015 ,Vol. 2/Issue 36/Sept. 07, Page 5575

25. PritiChaudhary et al. Knowledge, Attitude and Practice of Mothers regarding Diarrhoeal Illness in Children under Five Years of Age: A Cross Sectional Study in an Urban Slum of Delhi, India J. Commun. Dis.2014; 46(3):13- 21.

26. P S Thammanna, M Sandeep, P V Sridhar. Awareness among mothers regarding oral rehydration salt solution in management of diarrhea: A cross-sectional study .Indian J Child Health.Vol 2 | Issue 4 Oct-Dec 2015,,Page 215-218.

27. Shah MS, Ahmad A, Khalique N, Khan IM, Ansari MA, Khan Z. Do the mothers in rural Aligarh know about home based management of acute diarrhoea? Biology and Medicine, 2011, 3 (2) Special Issue: 7680.

28. Kaur,S. Chowdhury,R. Kumar;Mothers' Beliefs and Practices Regarding Prevention and Management of Diarrheal Diseases. Indian Pediatrics; January 1994-Volume 31.

29. AmitkumarRao, JyothiJadhav, Ranganath TS, LilianDsouza. Awareness regarding diarrhea, its prevention, and oral rehydration therapy among mothers of under-five children in urban slums of Bengaluru. International Journal of Medical Science and Public Health | 2015 | Vol 4 | Issue 8.page 1086-89.

30. Kaur P, Singh G. Food practices during diarrhea. IJPH 1994;38: 58-61.

31. SumanSaurabh, Umakant G Shidam, ManjulaSinnakirouchenan, MohsinaSubair, Loo GuoHou, Gautam Roy. Knowledge and practice regarding oral Rehydration therapy for acute diarrhea Among mothers of underfive children in an Urban area of puducherry, India. National Journal of Community Medicine/Volume 5|Issue 1 | Jan - Mar 2014,page 100-104.

32. DM Kadam, $\mathrm{R}$ Hadaye and $\mathrm{D}$ Pandit .Knowledge and practices regarding oral rehydration therapy among mothers in rural area of Vasind, India. Nepal Med Coll J 2012; 15(2): 110-112.

33. Vivechana et al. A study of diarrhoea management and literacy among Children under five years of age in rural areas, Moradabad, U.P. Global Journal of Bioscience and .B., VOL.5 (1) 2016: 142-145.

34. AbhaMangal, VarunKumar,SanjeetPanesar, RichaTalwar, Deepak Raut, Saudan Singh. Updated BG Prasad Socioeconomic Classification, 2014: A Commentary.[Downloaded free from http://www.ijph.in on Wednesday, July 01, 2015, IP: 115.111.224.207]. Indian Journal of Public Health, Volume 59, Issue 1, January-March, 2015; Page 42-44. 